\title{
AGEING MODELS AND ACCELERATED AGEING TESTS OF GLASS FIBER REINFORCED CONCRETE
}

\author{
Rimvydas MOCEIKIS ${ }^{1 *}$, Asta KIČAITE் ${ }^{1}$, Gintautas SKRIPKIŪNAS ${ }^{1}$, Aleksandrs KORJAKINS² \\ ${ }^{1}$ Department of building materials and fire safety, Vilnius Gediminas Technical University, \\ Sauletekio al. 11, Vilnius, Lithuania \\ ${ }^{2}$ Institute of materials and structures, Riga Technical University, Kalı ku iela 1, Centra rajons, Rīga, Latvija
}

Received 23 January 2018; accepted 28 February 2018

\begin{abstract}
Glass fiber reinforced concrete (GRC) is used for 40 years to create world's most stunning and complex architectural elements due to its high mechanical properties, particularly flexural strength. Yet it is very important to note that any type of glass fibers in the concrete matrix are undergoing complex ageing processes, resulting to significant decrease of initial mechanical characteristics of this composite material under natural weathering conditions. Aspects of GRC durability are mainly dependent from the properties of fibers and interaction between them and concrete matrix. In this article, long term strength retention of this composite material is discussed, existing experimental data of weathering tests presented, and main corrosion mechanisms explained. Lack of knowledge about freeze- thaw resistance of glass fiber reinforced concrete is addressed. Finally, latest attempts of GRC durability improvement are reviewed, such as adding micro fillers, polymers to the concrete matrix and enhancing surface of fibers in Nano scale.
\end{abstract}

Keywords: glass reinforced concrete, glass fibers, durability, static fatigue, freeze- thaw.

\section{Introduction}

Glass fibre- reinforced concrete (GRC) is a composite material that consists of cementitious matrix in which short glass fibers are dispersed. In this form, both fibers and concrete matrix retain their physical and chemical identities, yet resulting in a combination of properties that cannot be achieved by these materials alone. In general, fibers are the key for flexural strength and cementitious matrix acts as a load transfer medium between them. Standard GRC mix consists of fine silica sand, ordinary Portland cement (OPC), superplasticizer, $12 \mathrm{~mm}$ length alkali resistant glass fibers (ARG) and water. Microfilers and chemical additives, such as metakaolin, microsilica, dimension stabilizing admixtures, acrylic polymers and polyvinyl alcohol powder are used for GRC durability enhancement.

Every construction material, used in modern society must contain information about its one of the most important characteristics, referred to as long- term strength retention. Usually, due to many complex physical and chemical processes happening in natural weathering conditions, long- term structural characteristics are decreasing with time.
According to The American Society of Civil Engineers (ASCE) calculations, the average maintenance- free life for a structure built today is approximately only 18,5 years (Abanilla et al., 2006). Ironically, every man- made modern building is far less durable than those produced by two millennia old technologies, such as Great Stupas of Sanchi in India (200 BC), the Pont du Gard in France (15 $\mathrm{BC})$ and the Pantheon in Rome (118 AD).

GRC is not an exception, offering unique durability. Misinterpretation of glass fiber reinforced concrete corrosion mechanisms can lead to serious structural problems. The main goal of this article is to discuss general ageing process of glass fiber reinforced concrete. Furthermore, several accelerated ageing test methods are reviewed and compared to real weathering conditions. And finally, durability improvement measures are presented.

\section{Ageing models}

As a building material, GRC was for the first time used in 1956 by Pilkington Bros, based on research and development done by the Building Research Establishment (BRE)

*Corresponding author. E-mail: rimvydas.moceikis@vgtu.lt 
in the UK (Rickard, 2015). Ordinary E-type glass fibers, used in this new composite material in the early days did not prove successful due to glass chemical corrosion in cement matrix. For that reason, in 1977 AR- type (alkali resistant glass) was introduced to the industry and gained strong position due to significantly higher durability. After 40 years of AR-type glass application as ordinary Portland cement matrix reinforcement it is generally assumed that GRC loses significant portion of its initial flexural strength (Figure 1). Long term flexural strength retention depends of mix composition and environment conditions, which must be established according to accelerated ageing tests.

During last 60 years huge amount of research has been done in the field of GRC durability by many scientists, but no conventional and solid ageing models have been proposed to assist GRC designer and manufacturer. Reading through various research articles on the subject, one can notice that most of them refer to the paper written by Litherland K. L. (Litherland, Oakley, \& Proctor, 1981). After collecting many empirical data, Litherland proposed accelerated GRC ageing method based on keeping specimens in hot water for several months. Even though Litherland did not propose a specific reason or model for decrease of strength, but strong correlation between GRC ageing process and warm water environment was found. For many years it was the most popular method for determining durability of this material. But since late 1990s' some researchers started arguing that this method cannot be used for modified mixes. Additives such as metakaolin, microsilica, blast furnace slag and fly ash excited complex pozzolanic reactions in elevated temperatures, that cannot be found in natural weathering conditions. Purnell proposed more complex understanding about ageing of GRC, offering glass static fatigue as the main reason (Purnell, 2001). In the following chapters several main ageing models of glass reinforced concrete will be discussed.

\subsection{Chemical corrosion}

Commercial silicate glass is usually made of various melted oxides $\left(\mathrm{SiO}_{2} 69,9 \%, \mathrm{Al}_{2} \mathrm{O}_{3} 2,6 \%, \mathrm{CaO} 5,4 \%, \mathrm{MgO} 3,6 \%\right.$, $\mathrm{Na}_{2} \mathrm{O} 16,8 \%$ ) which are unstable in aqueous solutions of different $\mathrm{pH}$ due to complex hydration processes (Figure 1). Migration of main glass component $\mathrm{SiO}_{2}$ into alkaline solution is a very slow process, but it drastically increases when $\mathrm{pH}$ is over 10 (Paul, 1977). Alkali resistant glass fibers are generally resistant to alkali attack but are not completely inert (Purnell, 2001). It is thought that reaction in aqueous and cement extract media commences with immediate dissolution of sodium ions followed by hydroxyl ion attack of the $\mathrm{Si}-\mathrm{O}-\mathrm{Si}$ glass network and dissolution of silicate ions:

$\mathrm{Si}-\mathrm{O}-\mathrm{Si}-\mathrm{O}^{-} \mathrm{Na}^{+}+\mathrm{H}_{2} \mathrm{O} \rightarrow \mathrm{Si}-\mathrm{O}-\mathrm{Si}-\mathrm{OH}+\mathrm{NaOH}$ $\mathrm{Si}-\mathrm{O}-\mathrm{Si}-\mathrm{OH}+\mathrm{OH}^{-} \rightarrow \mathrm{Si}-\mathrm{OH}+\mathrm{O}^{-}-\mathrm{Si}-\mathrm{OH}$.

Due to clear chemical degradation of regular glass in alkaline environment, it cannot be used as reinforcement of cement matrix, which usually has $\mathrm{pH}>12$. But in 1960's alkali resistant glass was developed just for this reason. The new composition was $\mathrm{SiO}_{2} 71 \%, \mathrm{ZrO}_{2} 16 \%$, $\mathrm{Na}_{2} \mathrm{O} 12 \%$ and $\mathrm{Li}_{2} \mathrm{O} 1 \%$. Majumdar A. J. produced alkali resistant glass filaments diameter around $10 \mu \mathrm{m}$ according to single tip furnace method and tested it for reaction with Portland cement in various temperatures from $20^{\circ} \mathrm{C}$ to $65^{\circ} \mathrm{C}$ Durability tests showed that new Zirconia modified glass filament still loses a portion of its pristine strength in alkali environment. Reaction speed is increasing together with temperature, but at ambient temperatures of $20^{\circ} \mathrm{C}$ no significant loss of strength was recorded, and long term tensile strength of Zirconia modified glass was recorded of around $1200 \mathrm{MPa}$ (Majumdar, West, \& Larner, 1977). Chemical corrosion process of new glass composition is represented in Figure 2.

Orlovsky J. studied influence of $\mathrm{pH}$ on durability of AR glass filaments which were stored in alkaline solution with $\mathrm{pH} 13,5$ at temperature of $50^{\circ} \mathrm{C}$ without applied load. After 45 days the tested samples showed up to $60 \%$ loss of their initial tensile strength. The authors measured diameter of filaments and found no significant reduction. After studying the surface of aged glass filaments with SEM at

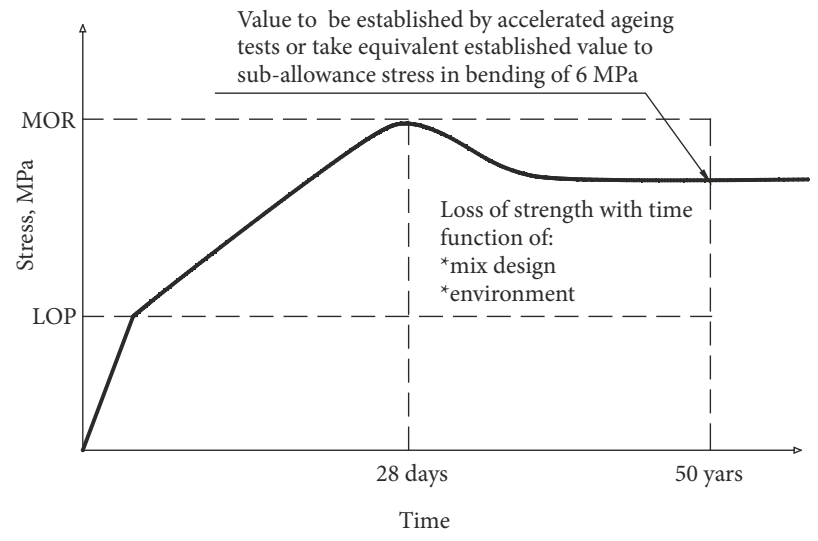

Figure 1. GRC loss of strength with time. Extract from Australian code of practice for GRC (Rickard, 2015)

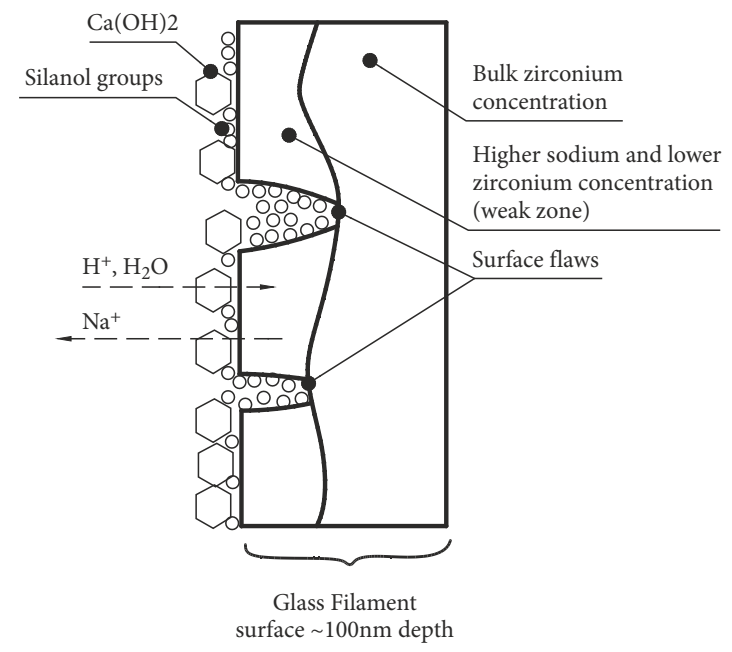

Figure 2. Chemical processes on the glass filament surface (Orlowsky, Raupach, Cuypers, \& Wastiels, 2005) 
200-1000 nm resolution they found individual defects on them with size around $40 \mathrm{~nm}$ This experiment concluded, that ageing of Zirconia modified glass is not entirely chemical process and is related to uprising of localized flaws (Orlowsky et al., 2005).

\subsection{Static fatigue and Arrhenius relationship}

As it was mentioned before, chemical corrosion is not the main reason for tensile strength reduction of alkali resistant glass. This has been confirmed by many investigators, who found no evidence of fiber cross section reduction after ageing tests (Bentur, 1985; Cohen \& Constantiner, 1985; Diamond, 1985; Jaras \& Litherland, 1975). In 2001 Purnell offered a new approach claiming that the main cause of GRC weakening with time is the growth of flaws on the fiber surface. This phenomenon is called static fatigue in glass technology literature and is described as constant breaking of $\mathrm{SiO}_{2}$ bonds at the tips of pre-existing flaws due to static load (Figure 3 ). The process also depends on such factors as glass composition, $\mathrm{pH}$, stress level, temperature, and fiber coating. Static fatigue can lead to spontaneous failure when glass is subjected to stress less than its bulk failure stress.

Knowing the fact that GRC ageing reaction rate is temperature dependent, Purnell used the

Arrhenius relationship and results of previous accelerated tests to describe flexural strength $S$ after time $t$ :

$$
S=\frac{1}{\sqrt{1+k_{0} e^{\left(-\frac{\Delta G}{R T}\right)} \cdot t}},
$$

where: $t$ is the age of GRC, T-ageing temperature, $R$ universal gas constant, $\Delta G$ - activation energy of the corrosion process and $k_{0}$ - pre-exponential term for strength loss. It is important to note, that $k_{0}$ is specific to a given matrix formulation at a given temperature and $\Delta G=89$ $93 \mathrm{~kJ} \mathrm{~mol}^{-1}$ for ordinary Portland cement matrix.

Further experiments with modified GRC matrix showed that formulations with metakaolin or sulfo-aluminates, which produce less $\mathrm{Ca}(\mathrm{OH})_{2}$ have activation energy for the strength loss $\Delta G=57-59 \mathrm{~kJ} \mathrm{~mol}^{-1}$, which is much less than ordinary OPC. According to formula 1, concrete matrix with less activation energy will have better durability (Purnell \& Beddows, 2005; Purnell, Cain, Itterbeck, \& Lesko, 2008).

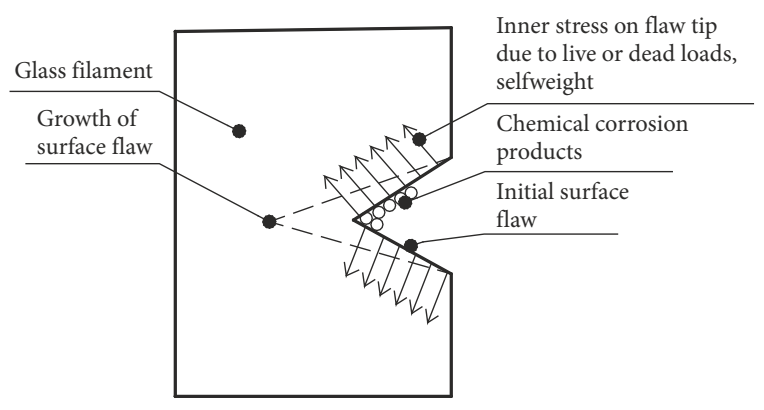

Figure 3. Fiber surface flaw growth due to inner stress (Purnell \& Beddows, 2005)

\subsection{Fiber- matrix bond and densification}

The fiber- matrix bond can be determined by pullout tests using the same glass strand from which fibers are produced. Due to the fact, that strand consists of many single filaments which are layered over each other, only the outer filaments that are in direct contact with the matrix, are receiving most of the tension forces. The deeper filaments are acting in the load transfer process only by the friction, so it is more frictional bond rather than interfacial bond.

Laws V. conducted glass fiber pull- out tests with various pull- out lengths varying from $1,5 \mathrm{~mm}$ to $10 \mathrm{~mm}$. Fibers were in the form of strand consisting of approximately 200 individual filaments, each 12,5 $\mu \mathrm{m}$. Results showed, that the best strand anchorage is achieved with $10 \mathrm{~mm}$ embedment in the matrix, giving about $0,4 \mathrm{kN}$ pull- out strength for a ssingle strand. The bond strength also increased with time, when specimens were stored in water at $20^{\circ} \mathrm{C}$ (Laws, Langley, \& West, 1986).

Butler, Mechtcherine, and Hempel (2009) studied the SEM images of the fiber surface after they were pulledout from the matrix. Test results showed, that the main reason for poor anchorage is the coarse, brittle Portlandite phases, that dominate in OPC cement matrix (Figure 4). In contrast, much better durability and fiber anchorage was observed when cement clinker content was low and pozzolanic fines are used, which decreases the alkalinity of the pore solution.

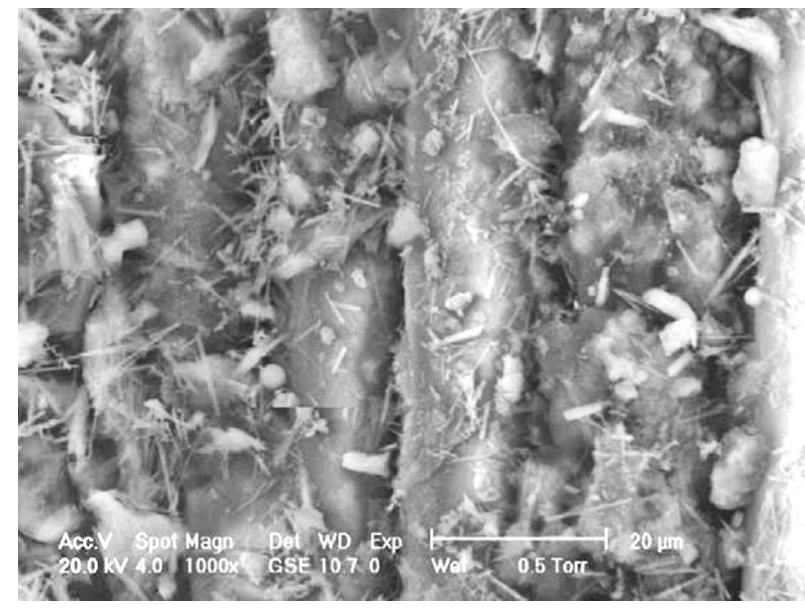

Figure 4. ESEM image of VET-02 filaments in Matrix M3 after 28 days of accelerated ageing (Butler et al., 2009)

Manny scientists (Purnell, Short, Page, \& Majumdar, 1999; Huijun, Jing, Zhomgehang, \& Ting, 2013; Mills, 1981) agree on the fact that $\mathrm{Ca}(\mathrm{OH})_{2}$ plays a negative role due to densification of fiber- matrix interface. Microscopic images show that $\mathrm{Ca}(\mathrm{OH})_{2}$ crystals have wedged structure and can potentially cause flaws on the surface of filaments during the matrix crystallization and buildup of the lateral pressure. This results to initial defects on the filaments and further static fatigue process, described previously. 


\subsection{Temperature and moisture gradients}

GRC usually has about 3-4 times more cement then ordinary normal weight concrete. This results in a very dense and complex capillary system through which moisture can migrate. Swelling and drying of any building material can raise internal stress and cracking. Theodorakopoulos investigated deformations of thin GRC sheets due to swelling and drying. He found that for premix GRC exposed to alternating wet and dry environment maximum shrinkage and swelling strain is between $0,08-0,12 \%$ in laboratory conditions during maximum 96-day period (Theodorakopoulos, 1995).

Deformations of GRC sheets were monitored under ambient conditions ( 5 years in Turkey climate), with temperature variation from $-7^{\circ} \mathrm{C}$ to $37^{\circ} \mathrm{C}$. Outdoor shrinkage strain was found to be up to $0,25 \%$ and swelling up to $0,18 \%$. No cracking was found on the surface of specimen during whole experiment (Ispir, Dalgic, Hajihosseinlou, \& Ilki, 2015).

Correia R. studied rehabilitation case of cracked 20-year-old GRC building facade. Extensive cracking and panel deformation were the results of using non-alkali resistant glass fibers and taking no account for ageing process. Experimental tests showed that daily peak temperature differentials resulted in tension stresses up to 4-6 $\mathrm{MPa}$ in the GRC elements, when direct tension resistance of aged material was found to be only 2,5 $\mathrm{MPa}$ (Correia et al., 2005).

Defects from temperature and moisture gradients can be avoided if good design practice of GRC-to-structure connections is used. Less stiff fixings usually minimize the effects of imposed strains, that lead to internal stresses.

\subsection{Carbonization}

Carbonization is very slow chemical process when $\mathrm{Ca}(\mathrm{OH})_{2}$ reacts with $\mathrm{CO}_{2}$ to form a new mineral, called calcite $\left(\mathrm{CaCO}_{3}\right)$ that is stronger than $\mathrm{Ca}(\mathrm{OH})_{2}$ phase, which gives higher compressive strength of concrete. During this reaction, alkalinity of concrete decreases drastically which means no more protective envelope for the rebar in regular concrete. On the contrary, lower alkali content is better for glass fibers, that are acting as reinforcement of the GRC matrix. Growing $\mathrm{CaCO}_{3}$ crystals are filling the voids and densifying the matrix, which becomes stronger and tougher up 70\%, compared to initial state (Figure 5). Bond is increasing due to bigger interaction area in the fiber- matrix interface and the composite results in higher flexural strength.

Purnel P. investigated effect of super- critical carbonation $\left(\mathrm{scCO}_{2}\right)$ on the glass reinforced concrete. GRC samples were exposed to saturated $\mathrm{scCO}_{2}$ at $98 \mathrm{bar}(10 \mathrm{MPa})$ and $59^{\circ} \mathrm{C}$ for $24 \mathrm{~h}$ and then aged according to accelerated ageing method by immersion in hot water for 56 days. The treatment increased mechanical properties of the matrix up to $70 \%$, fiber matrix bond up to 3 times and aged GRC samples proved significant retention of toughness (Purnel et al., 2001).

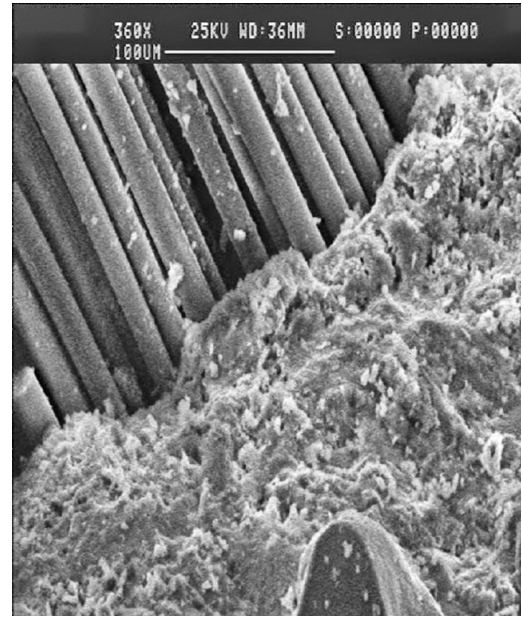

Figure 5. Scanning electron micrograph: aged (28 days) carbonated sample (Purnell, Short, \& Page, 2001)

\section{Accelerated ageing tests}

Various accelerated ageing test methods were developed during last 40 years. Most widely prescribed are the immersion in hot water and wet- dry cycling. Both are well correlated with the UK and similar wet- dry climate zones with temperatures above $0{ }^{\circ} \mathrm{C}$. As for freeze- thaw resistance, there are no specific methods linked to GRC that can be used with no doubt in practice.

Some test methods which are used in ordinary concrete practice, could be considered as adequate for GRC thin structures. Several standards, designed for testing concrete surface scaling at freezing can be used for GRC (SS 137244:1995; CEN/TS 12390-9:2006; LST 1428.19). Prediction methods based on concrete porosity can also be helpful, when there is no need to test GRC flexural strength retention after freezing and thawing. Such prediction method is described in section 2.4.

\subsection{Immersion in hot water}

First real GRC ageing data was presented in 1979 by Building Research Establishment (UK) after 10 years of ageing in natural climate conditions. Later, in 1982 Litherland, Oakley and Proctor developed unique accelerated test methods for determining long term durability of direct rowing (S.I.C. test) and glass fibre reinforced composite. Experimental ageing results were extrapolated for hundred years of exposure in UK environment and methods described were relatively easy to implement in practice. The S.I.C. test was developed to gain direct knowledge about tensile strength of fibers in real cement matrix. And accelerated ageing test of sprayed GRC composites showed retention of flexural strength.

Both mentioned methods are based on keeping series of specimens in water with temperatures from 4 to $80^{\circ} \mathrm{C}$ for various periods of time, up to 3 years. Litherland plotted results of flexural strength vs ageing period (days) and found that flexural strength is decreasing in parallel lines on logarithmic time scale for all temperatures, dropping 
from $30 \mathrm{MPa}$ to a constant region of $12 \mathrm{MPa}$, which can be referred as residual strength of the composite. Accelerated ageing test results were compared to 10 - year monitoring of GRC in real conditions (Building Research Establishement Information Paper CP38/79, 1979). It was assumed, that maintaining GRC sample immersed in $50{ }^{\circ} \mathrm{C}$ water for 1 day is equivalent to 90 days of weathering in actual climate of the UK.

\subsection{GRC with modified matrix}

Previous section describes accelerated ageing of GRC with typical OPC matrix. In our days many are using chemically active micro filers, such as metakaolin, fly ash, microsilica, blast furnace slag ect., to enhance various characteristics of GRC composites. According to latest research data, immersion in hot water technique cannot be used for GRC with modified matrix due to complex pozzolanic reactions in elevated temperatures, that usually are not common in real climate.

Purnell P. discussed validity of immersion in hot water for GRC with modified matrices. Three types of samples with OPC, sulphoaluminate and metakaolin modified matrices were stored in water at temperatures 20, 38 and $65^{\circ} \mathrm{C}$ for one year. A predictive model has been suggested whereby these accelerated ageing regimes can be correlated with longer natural exposure periods via Arrhenius type relationship. Flexural tests after one year showed no significant strength reduction for samples that were kept in 20 and $38^{\circ} \mathrm{C}$. On the other hand, in $65^{\circ} \mathrm{C}$ hot water samples were degrading rapidly. OPC matrix showed strong correlation with Litherland, fitting very near the original curves of the original model. Both modified matrices were acting very unusual, at first up to 28 days strength was growing and then dropping rapidly (Purnell et al., 1999). Other further attempts with modified GRC matrices also showed similar inconsistencies with the old model (Peled, Jones, \& Shah, 2005; Purnell et al., 2001).

\subsection{Micro-indentation}

A new method for studying ageing of GRC was developed by Bartos M. J. and Zhu W. This technique was based on Vickers micro hardness testing in the fiber- matrix interaction zone and within the bundle of fibers. Micro indentation apparatus Microtest 200 was used in the tests and produced very small loads with triangular shape needle, in the resolution of $0,7 \mathrm{mN}$ and $1,7 \mathrm{~nm}$. Microhardness was tested in several places: cement matrix, fiber- matrix interface and within the fibre bundle. Results showed, that embrittlement of the water- aged GRC was closely related with increase of micro- hardness values in the interface and within the fiber bundle. For standard OPC matrix, micro- hardness values between aged and un- aged composites differed as follows: $60 \%$ in the matrix, $10 \%$ in the interface zone, $140 \%$ in the middle of fiber bundle (Bartos \& Zhu, 1996). Following fiber push-in tests, done by
Zhu W. and Bartos M. J. showed that resistance to fiber sliding increased significantly due to ageing. Knowing frictional properties of fibers is also important, because during tension stress the core might pull out from the fiber bundle if friction between filaments is too low (Zhu \& Bartos, 1997).

Above described tests prove, that micro- indentation can be very useful tool for investigating ageing process of GRC composites. First of all- for its computational data which is more direct measurement than SEM microscopy, that gives only qualitative information which is difficult to relate to the true interfacial properties. Also, detection of interfacial films is very difficult with SEM due to their fragility and very different interfacial microstructure can be observed in different parts of the same sample.

\subsection{Freeze- thaw resistance}

Through all the years of GRC research, there was very little attention addressed to freeze- thaw resistance of this building material. It could be connected to the fact that GRC is mostly used in warm- wet climate zones, such as Australia, China, Saudi Arabia, USA, Spain, Great Britain. European standard EN 15191 offers to test freeze thaw durability according to EN 13198 . The test procedure includes 25 freeze- thaw cycles, where one cycle is cooling down specimens to $-20^{\circ} \mathrm{C}$ in 2 hours and thawing in +20 ${ }^{\circ} \mathrm{C}$ warm water for 2 hours. In the test report, number of visible projections, depressions and flakes for surface of the specimen are given.

Enfedaque A. tested freeze- thaw resistance of GRC in a very similar way as described above. After 50 cycles in climatic chamber, GRC with OPC formulation lost about $40 \%$ of initial flexural and $80 \%$ of strain capacity, becoming a more brittle material with less bending strength (Enfedaque, Paradela, \& Galvez, 2012).

Any type of concrete matrix resistance to freezing and thawing can be predetermined according to porosity parameters, which are measured with water absorption kinetics. According to GOST 12730.4-78, closed and open porosity of concrete is measured (air and capillary pores). Also, parameters indicating pore size distribution are identified: $\lambda$ - mean value and $\alpha$ - uniform size. Freezethaw resistance $K_{F}$ is calculated according to formula 2:

$$
K_{F}=\frac{P_{c}}{0,09 P_{o}} \text {, }
$$

where, $P_{c}$ - closed porosity of concrete (air pores), $P_{o}-$ open porosity (capillary pores).

According to formula 2, frost resistant concrete is the one where volume of closed air pores $P_{c}$ is higher than increase of capillary water volume $P_{o}$ when it is turning to ice (about 9\%). For correct use of this method, correlation between water absorption kinetics and GRC freezethaw resistance according to actual wearing tests must be determined. 


\subsection{Wet- dry cycling}

In real wearing conditions, GRC is usually affected by series of wet- dry cycles instead of continuous immersion in water. Such cyclic weathering type test is described in EN 1170-8, which corresponds to natural weathering of the material during 10-20 years of exposure in conditions without freezing and thawing. Test procedure requires climatic chamber with temperature regimes of 20 and $70{ }^{\circ} \mathrm{C}$, immersion in water and air ventilation. One full wet- dry cycle lasts 48 hours and generally consists of two phasesimmersion in $20^{\circ} \mathrm{C}$ and drying in $70^{\circ} \mathrm{C}$ hot air flow.

Even though EN 1170-8 weathering test is much closer to real conditions, very few scientists implement it in their GRC durability research and are using immersion in water. Enfedaque A. compared residual flexural strength of OPC GRC in conditions of wet- dry cycling (EN 1170-8 method) and freezing- thawing in dry climatic chamber with $+20 /-20{ }^{\circ} \mathrm{C}$ temperature fluctuation. Four- point bending test values obtained after 200 wet- dry cycles were very similar to 50 freeze- thaw cycles (Enfedaque et al., 2012). This fact brings to conclusion, that ageing of GRC in terms of flexural capacity can be adequately measured by freeze- thaw instead of wet- dry cycling, which is less common in cold climate countries and generally takes considerably less time to produce same results.

\section{GRC durability improvement}

Various measures proposed to improve the ageing performance of the GRC composites have been reviewed by many authors. These include changes of the chemical composition of the glass fibers, their surface treatment and modification of the matrix. As discussed in section 2.2., one should be cautious about choosing the proper weathering test for modified matrix, because immersion in water can provide inconsistent results.

\subsection{Polymers}

Acrylic polymers as additives for concrete were introduced in 1980's, increasing GRC panel early strength and allowing to refuse prolonged wet curing methods, used in production. In our days, polycarboxylate ether-based or superplasticizers allow us to use lower W/C ratio to achieve adequate concrete workability and therefore 7 day wet cure storage of concrete products is unnecessary.

Another application of acrylic polymer can be in the field of GRC durability improvement. Acrylic polymer suspension is usually added in quantities $7-10 \%$ from the weight of cement. Ball $\mathrm{H}$. reviewed durability data obtained from GRC coupons, naturally aged for 19 years in wet- dry climate. Ductility and flexural capacity dropped up to $40 \%$ in composites made without polymer after 19 years. On the other hand, GRC with $7 \%$ acrylic polymer maintained most of the toughness through all the mentioned period. Research also showed, that wet- dry cycling accelerated ageing is more compatible with real weathering data for polymer- modified composites (Ball, 1993).
Qian X. investigated effect of PVA (polyvinyl alcohol) powder on durability of GRC. Immersion of $6 \mathrm{~mm}$ thickness coupons in $20^{\circ} \mathrm{C}$ water was chosen for ageing mechanisms. Direct tensile tests showed that PVA powder increases ductility and tensile strength during ageing. Microstructural analysis explained the positive effect of PVA powder, which created protective thin films of polymer on the glass fiber surface and prevented the accumulation of brittle calcium hydroxide in the interfacial zone (Qian, Shen, Mu, \& Li, 2003).

\subsection{Micro filers}

It was previously discussed, that one of the main causes of GRC deterioration is growth of flaws on fiber surface due to growth of portlandite crystals. Manny kinds of microfillers can decrease this process with pozzolnanic reactions with portlandite phase.

Peled A. discovered very positive effect of dimension stabilizing admixture on GRC durability. Super low contractile admixture significantly decreased free shrinkage of the matrix. Immersion in hot water was chosen for accelerated test method. After 84 days in $50{ }^{\circ} \mathrm{C}$ water (equivalent to 23 years in UK climate) standard GRC lost $25 \%$ of initial strength, when modified GRC with contractile admixture even increased flexural strength by $20 \%$ (Peled et al., 2005).

Brandt A. M. and Glinicki M. A. studied how metakaolin influenced durability of GRC. Reference specimens lost $85 \%$ of initial ultimate tensile strain and $30 \%$ of tensile strength after 84 days immersion in $50{ }^{\circ} \mathrm{C}$ water. On the other hand, specimens with $40 \%$ replacement of cement with metakaolin even slightly increased both characteristics after the same ageing conditions. SEM-EDX showed no maleficent portlandite phase in the contact zone between fibers and the matrix, which explained enhanced durability of GRG modified with metakaolin (Brandt \& Glinicki, 2003).

Microsilica is known for ability to alter cement paste structure due to pozzolanic reaction with cement hydration products. New hydrated minerals result in a denser matrix and higher compressive strength of concrete. As for GRC, where tensile strength of the composite is the key issue, microsilica does not contribute much in enhancement of flexural or tensile strength. Bartos J. M. and Zhu W. found that microsilica does not significantly improve the ageing performance of GRC composites when used as a modification of the matrix (Bartos \& Zhu, 1996).

\subsection{Fiber surface modification}

Glass fibers usually have initial flaws (microcracks) on the surface, which emerges due to bulk handling, transportation and mixing. Various glass filament surface treatment techniques are used to enhance fiber mechanical and chemical resistance in cementitious matrix.

New commercially available alkali resistant glass fibers have few nanometers thick organosilane coating. Zinck P. 
and Rothe C. researched interaction between coupling agents and glass fibers. This kind of sizing forms threedimensional polymer network on the glass surface which improves fiber matrix bond, protects fibers from moisture and enhances mechanical properties of fibers. Direct tensile tests of glass fibers showed increased tensile strength, which was explained by flaw healing action of organosilane coating and higher fracture energy of modified filaments (Zinck, Pays, Rezakhanlou, \& Gerard, 1999; Rothe, Gao, Plonka, \& Mader, 2015).

Further durability tests of organosilane coatings showed significant reduction of sizing in concentrated $\mathrm{NaOH}$ solutions at ambient and elevated temperatures. Styrene- butadiene dispersions proved to be most resistant between tested polymer coatings (Mader \& Plonka, 2004).

Latest studies show remarkable improvement of mechanical properties and durability for ARG fibers enhanced with carbon nanotube reinforced nanoclay coatings. Fiber tensile strength with such sizing is found to be higher by $50 \%$ after treatment in $5 \mathrm{wt} \% \mathrm{NaOH}$ aqueous solution for seven days in ambient conditions (Gao, Mader, \& Plonka, 2007).

\section{Conclusions}

Even though alkali resistant AR-type glass fibers are used for GRC production, it still loses significant portion of initial flexural and tensile strength under natural wearing conditions. The main reason for strength loss is flaw growth on the surface of glass filaments, a process called static fatigue, which is not yet fully understood by scientists.

For typical GRC with OPC matrix, immersion in warm water can be used as accelerated test method for long term strength retention evaluation. As for GRC modified with reactive micro fillers (metakaolin, micro silica, fly ash, blast furnace slag), wet- dry cycling according to EN 1170-8 is recommended due to additional chemical processes acting in warm water which are not common ir natural environment.

Scaling at freezing and thawing test methods can replace immersion in water and wet- dry cycling, because actual test results show significant flexural strength reduction, like other two.

Several techniques can be used for GRC durability enhancement, such as chemically active microfillers, reducing porlandite quantity in cement matrix, acrylic and PVA polymers and various coatings of fiber surface (organosilane, styrene- butadiene, nanoclay).

\section{Disclosure statement}

Authors declare that they do not have any competing financial, professional, or personal interests from other parties.

\section{References}

Abanilla, M. A., Azhari, F., Banthia, N., et al. (2006). Durability of fibre reinforcef polymers in Civil infrastructure (Durability Monograph). ISIS Canada reseach network.

Bentur, A. (1985). Proceedings in PCI symposium: Durability of Glass Fibre Reinforced Concrete (108 p.). Illinois, USA.

Butler, M., Mechtcherine, V., \& Hempel, S. (2009). Experimental investigations on the durability of fibre-matrix interfaces in textile-reinforced concrete. Cement and Concrete Composites, $31,221-231$.

https://doi.org/10.1016/j.cemconcomp.2009.02.005

Building Research Establishment Information Paper CP38/79. (1979). Properties of GRC: ten year results.

Bartos, M. J., \& Zhu, W. (1996). Effect of microsilica and acrylic polymer treatment on the ageing of GRC. Cement and Concrete Composites, 18, 31-39.

https://doi.org/10.1016/0958-9465(95)00041-0

Ball, H. (1993). Durability of naturally aged, GFRC mixes conaining Forton Polymer and SEM analysis of the facture interface. Recommended Practice for Glass Fiber Reinforced Concrete Panels (4th ed.). MNL-128-01. PCI, Chicago, IL.

Brandt, A. M., \& Glinicki, M. A. (2003). Effects of pozzolanic additives on long- term flexural toughness of HPGRC. Fourth international workshop on high performance fiber reinforced cement composites. University of Michigan and the University of Stuttgard.

Cohen, M. D., \& Constantiner, D. (1985). Proceedings in PCI symposium: Durability of Glass Fibre Reinforced Concrete (158 p.). Illinois, USA.

CEN/TS 12390-9:2006. Testing hardened concrete. Freeze-thaw resistance. Scaling.

Correia, R., Ferreira, J., Branco, A. (2005). A rehabilitation study of sandwich GRC façade panels. Construction and Building Materials, 20, 554-561.

Diamond, S. (1985). Proceedings in PCI symposium: Durability of Glass Fibre Reinforced Concrete (199 p.). Illinois, USA.

Enfedaque, A., Paradela, L. S., \& Galvez, V. S. (2012). An alternative methodology to predict aging effects on the mechanical properties of glass fiber reinforced cements (GRC).

EN 1170-8:2008. Test method for glass-fibre reinforced cement. Cyclic weathering type test.

EN 15191:2009. Precast concrete products. Classification of glassfibre reinforced concrete performance.

EN 13198:2003. Precast concrete products. Street furniture and garden products.

GOST 12730.4- 78:1980. BETONY. Metody opredeleniya pokazateley poristosti.

Gao, S. L., Mader, E., \& Plonka, R. (2007). Nanocomposite coatings for healing surface defects of glass fibers and improving interfacial adhesion. Composites Science and Technology, 68, 2892-2901. https://doi.org/10.1016/j.compscitech.2007.10.009

Huijun, W., Jing, Z., Zhomgehang, W., \& Ting, S. (2013). Damage action of Alkali- resistant Glass Fiber in Cement- based Material. Journal of Wuhan University of Technology- Mater Sci. Ed., 28(4), 761-765. https://doi.org/10.1007/s11595-013-0765-7

Ispir, M., Dalgic, K. D., Hajihosseinlou, S., \& Ilki, A. (2015). Long term deformation monitoring of GRC façade panels under ambient conditions. GRCA congress 2015 proceedings. 
Jaras, A. C., \& Litherland, K. L. (1975). Proceedings in RILEM symposium: Fibre Reinforced Cement and Concrete (327 p.).

Litherland, K. L., Oakley D. R., \& Proctor B. A. (1981). The use of accelerated ageing procedures to predict the long term strength of GRC composites. Cement and Concrete Research 11, 455-466. https://doi.org/10.1016/0008-8846(81)90117-4

Laws, V., Langley, A. A., \& West, J. M. (1986). The glass fibre/ cement bond. Journal of Materials science, 21, 289-296. https://doi.org/10.1007/BF01144734

LST 1428.19. Betonas. Bandymo metodai. Atsparumo šalčiui nustatymas vienpusio šaldymo būdu.

Majumdar, A. J., West, J. M., \& Larner, L. J. (1977). Properties of glass fibres in cement environment. Journal of Materials Science, 12, 927-936. https://doi.org/10.1007/BF00540975

Mills, R. H. (1981). Preferential precipitation of calcium hydroxide on alkali- resistant glass fibers. Cement and Concrete Research, 11, 689-697. https://doi.org/10.1016/0008-8846(81)90027-2

Mader, E., \& Plonka, R. (2004). Coatings on alkali- resistant glass fibres for the improvement of concrete. Journal of Industrial Textiles, 33, 191-208. https://doi.org/10.1177/1528083704039833

Orlowsky, J., Raupach, M., Cuypers, H., \& Wastiels, J. (2005). Durability modeling of glass fibre reinforcement in cementitious environment. Materials and Structures, 38, 155-162. https://doi.org/10.1007/BF02479340

Purnell, P. (2001). A static fatigue model for the durability of glass fibre reinforced cement. Journal of Materials Science, 36, 5385-5390. https://doi.org/10.1023/A:1012496625210

Paul, A. (1977). Chemical durability of glasses: a thermodynamic approach. Journal of Materials Science, 12, 2246-2268. https://doi.org/10.1007/BF00552247

Purnell, P., \& Beddows, J. (2005). Durability and simulated ageing of new matrix glass fibre reinforced concrete. Cement and Concrete Composites, 27, 875-884.

https://doi.org/10.1016/j.cemconcomp.2005.04.002

Purnell, P., Cain, J., Itterbeck, P., \& Lesko, J. (2008). Service life modeling of fibre composites: a unified approach. Composites Science and technology, 68, 3330-3336.

https://doi.org/10.1016/j.compscitech.2008.08.026
Purnell, P., Short, N. R.; Page, C. L., Majumdar, A. J. (1999). Accelerated ageing characteristics of glass-fibre reinforced cement made with new cementitious matrices. Composites: Part A, 30, 1073-1080. https://doi.org/10.1016/S1359-835X(99)00019-6

Purnell, P., Short, N. R., \& Page, C. L. (2001). Super- critical carbonation of glass- fibre reinforced cement. Composites Part A: Applied science and manufacturing, 32, 1777-1787. https://doi.org/10.1016/S1359-835X(01)00019-7

Peled, A., Jones, J., \& Shah, S. P. (2005). Effect of matrix modification on durability of glass fiber reinforced cement composites. Materials and Structures, 38, 163-171. https://doi.org/10.1007/BF02479341

Qian, X., Shen, B., Mu, B., \& Li, Z. (2003). Enhancement of aging resistance of glass fiber reinforced cement. Materials and structures, 36, 323-329. https://doi.org/10.1617/13843

Rickard, C. (2015). GRC developments in Australia. GRCA congress 2015 proceedings.

Rothe, C., Gao, L. S., Plonka, R., \& Mader, E. (2015). Nano surface structuring of alkali- resistant glass fibres for multifunctional effects. 1st International Conference Textile Reinforced Concrete. Leibniz Institute of Polymer Research Dresden, Germany.

SS 137244:1995. Concrete testing. Hardened concrete. Scaling at freezing.

Theodorakopoulos, D. D. (1995). Shrinkage behaviour of GRC Thin Sheets. Cement and Concrete Composites, 17, 229-238. https://doi.org/10.1016/0958-9465(95)00013-3

Zhu, W., \& Bartos, M. J. (1997). Assessment of interfacial microstructure and bond properties in aged GRC using a novel microindetation method. Cement and Concrete Research, 27, 1701-1711. https://doi.org/10.1016/S0008-8846(97)00155-5

Zinck, P., Pays, M. F., Rezakhanlou, R., \& Gerard, J. F. (1999). Mechanical characerisation of glass fibres as an indirect analysis of the effect of surface treatment. Journal of Materials Science, 34, 2121-2123. https://doi.org/10.1023/A:1004572112470 